\title{
EL QUIEBRE EPISTEMOLÓGICO Y EL SURGIMIENTO DEL NUEVO SUJETO DE CONOCIMIENTO EN LA HISTORIA GENERAL Y NATURAL DE LAS INDIAS DE GONZALO FERNÁNDEZ DE OVIEDO
}

\author{
Luz Ángela Martínez \\ Universidad de Chile \\ luzmartine@gmail.com
}

\section{RESUMEN/ABSTRACT}

La Conquista del Nuevo Mundo propició un cambio fundamental en la historia del conocimiento y anticipó fenómenos que luego vemos aparecer como motores fundamentales de la revolución cientifica acaecida entre el siglo XVI y el XVII. El presente artículo busca demostrar que estos fenómenos ya pueden ser apreciados en la obra del cronista Gonzalo Fernández de Oviedo y que la aparición de ellos está íntimamente relacionada con la experiencia de la naturaleza americana. De tal manera, se quiere asentar la importancia del nuevo mundo en la concepción de la ciencia moderna.

Palabras clave: Gonzalo Fernández de Oviedo. conocimiento y ciencia colonial. Conquista y cambio epistemológico.

The Conquest of the New World was at the basis of a highly significant change in the history of knowledge and it anticipated several processes which we will later see as important motivating factors in the scientific revolution of the sixteenth and seventeenth centuries. In this essay, we intend to demonstrate that these processes may already be observed in the writing of the Spanish chronicler Gonzalo Fernández de Oviedo; its presence is to be closely related to the experience of American nature. The importance of the New World is thus seen as a major event in the conception of modern science.

KEY WORDS: Gonzalo Fernández de Oviedo, knowledge, Colonial Science, Conquest, epistemological change. 
Como bien se sabe y declara el mismo Gonzalo Fernández de Oviedo en su Historia General y Natural de las Indias, la base epistemológica y categoría de verdad en las que funda y valida su quehacer de historiador natural se fusionan en el criterio de "lo visto por los ojos" ó "lo visto y lo vivido" (Oviedo, Historia 11). Esto es, en resumidas cuentas, lo que el sujeto de conocimiento -el "testigo de vista"-, deseoso de indagar en los misterios de la Naturaleza, experimenta de manera directa y registra luego en la órbita de un saber, ya sea el de la cosmografía, la naciente botánica, la zoología o cualquier otro ámbito del conocimiento científico enmarcado por la Filosofía Natural. Después de "lo visto", en segundo lugar Oviedo establece el criterio de "lo oído"; es decir, el relato que el historiador o cronista recogía de un testigo presencial y directo de un hecho natural, de un suceso histórico o de un fenómeno social. En último lugar, Oviedo alude constante y negativamente un tercer criterio procedente de la tradición escolástica y de la más cercana esfera humanista. Se trata, como también se sabe, del criterio de "lo leído", conformado por el conjunto de teorías y obras provenientes de la tradición que, en definitiva, referían al "prestigioso saber de los antiguos", con el cual el sujeto de conocimiento del siglo XV y aun del XVI cotejaba, verificaba y validaba su propio saber.

En tanto la de Oviedo constituye una de las visiones más importantes de la naturaleza americana, los principios epistemológicos en que se basa, la capacidad representativa de su lenguaje y los distintos grados de "invención"/ objetividad que involucra, han sido revisados desde distintos puntos de vista y objeto de larga discusión crítica ${ }^{1}$. Sin perder de vista aquello, pero sin ser el objeto de este trabajo, a donde me interesa orientar la reflexión es hacia el

\footnotetext{
1 Sin duda, la vida y obra de Oviedo han sido estudiadas desde distintos puntos de vista y objeto de muy diferentes valoraciones. Desde la panegírica Introducción que hiciera José Amador de los Ríos a la edición de la Historia general y natural de las Indias, Madrid, 1851, hasta la década de los 50, pervivió una imagen apologética de Oviedo que la crítica contemporánea se ha encargado de contradecir con profusa documentación y duros epítetos. Tal como reseña Juan Pérez de Tudela y Bueso en su "Estudio Preliminar" de la Historia de 1959, de los 50 en adelante la semblanza espiritual y posición ideológica de Oviedo ha sido duramente debatida por la crítica. El punto de inflexión entre la imagen apologética de Oviedo y su revisión actual, lo marca José de la Peña y Cámara en "Contribuciones documentales y críticas para una biografía de Gonzalo Fernández de Oviedo", en Revista de Indias, núms. 69-70. Madrid, 1957. En este trabajo fundamental de la Peña y Cámara aporta una serie de datos para una biografía objetiva del cronista y denuncia la sesgada parcialidad -incluso el escamoteo de datos- que atraviesa la obra de de los Ríos. Esta revisión general de los años
} 
sistema de contradicciones que subyace al sistema de conocimiento de nuestro Primer Cronista de Indias. Partamos entonces por advertir que en el momento en que Oviedo manifiesta su posición respecto del "saber de los antiguos", el criterio de "lo leído" no era un principio del saber cuya validez se encontrara exclusivamente en sí mismo. Su verdadera fortaleza se hallaba más bien en el Argumento de Autoridad, que resumió la inexpugnable asociación y/o identificación escolástica de las Sagradas Escrituras y la Filosofía Antigua, especialmente en lo que dice relación con el entendimiento de la naturaleza y el universo (Hull 171). No deja entonces de llamar la atención que frente a los más acreditados principios científicos de los siglos XV y XVI - "lo leído”- y su supremacía teológico-filosófica, el cristiano y ortodoxo cronista de la Corona tome tan decidida distancia y se muestre dispuesto a abandonar a su gran y único modelo, Plinio, y con él a Aristóteles, Ptolomeo, Santo Tomás de Aquino, San Jerónimo, entre otros de igual o mayor ascendencia filosófica, científica o teológica. Si seguimos la secuencia propuesta por el texto, no sorprende menos que frente a esas Autoridades pertenecientes a las más altas jerarquías religiosas y filosóficas, Oviedo oponga un "todos" vulgar como sujeto colectivo del saber y que afirme que este último es un hecho o suceso ordinario revelado directamente por la naturaleza, anulando con todo aquello la condición extraordinaria o "aurática" (Bejamin 15-57) del conocimiento2: "Mas, ¿para qué quiero traer autoridades de los antiguos

50 cierra, por así decirse, con la obra del mismo Tudela y Bueso, la que proporciona de ahí en adelante los biográficos datos fidedignos a los cuales ha recurrido la crítica posterior.

De los años sesenta hasta hoy, tres aspectos básicos han concitado el interés de los estudios. El primero, es el que viene ya desde los 50 y que tiene relación con el cuestionamiento de Oviedo como "historiador fidedigno" y su tendenciosa y denigrante visión de la naturaleza, la cultura indígena y el indio (Arrom 63-78; Miranda, "Introducción" 7-74). El segundo, tiene que ver con la biografía de Oviedo y con la significación de la Historia y del Sumario en relación con la imagen y conocimiento de la naturaleza del "nuevo mundo" (Gerbi, La disputa 25-27; Gerbi, La Naturaleza 151, 306, 319, 321; Bolaños 15-33).

2 El "sujeto vulgar y colectivo del saber", ciertamente debe ser relacionado con el "sujeto colectivo de la hazaña" proclamado por Bernal Díaz del Castillo a lo largo de toda su Historia verdadera de la conquista de la Nueva España. La importancia de aquella "vulgaridad" en relación con el tránsito del latín a la lengua vulgar en que se comienza a emitir el discurso científico y filosófico cobra toda su dimensión con lo informado por el historiador de la ciencia Hull, L.W. H. y el filósofo Ernst Cassirer. El primero señala: “...la autoridad ya no era capaz de impedir el progreso de la ciencia, como lo había sido en siglos anteriores. Hombres como Galileo y Descartes escribían ya en sus lenguas romances maternas, en vez de en latín. Sus ideas se difundían más rápida y ampliamente que la de sus predecesores" (Hull 179). El segundo: 
en las cosas que yo he visto, ni en las que Natura enseña a todos y se ven cada dia" "(Oviedo, Sumario 151).

Proyectada sobre el horizonte cultural de la primera mitad del siglo XVI, en el que el Argumento de Autoridad tenía la condición del dogma y el conocimiento era un ejercicio exclusivo de algunos círculos, la desobediencia y/o contradicción del historiador indiano sobrepasa sin duda la mera digresión y se erige como gesto revelador de la nueva y compleja actitud ante el saber científico que se está gestando -muy a pesar de la ortodoxia reinante- en el "nuevo mundo". En esta situación, lo primero a notar es que la contradicción a la Autoridad como postura científica, tensiona sincrónica y diacrónicamente las bases del sistema de conocimiento desde la Antigüedad hasta el siglo XVI; agreguemos de una vez que esa "tensión", lejos de resolverse, va a caracterizar de ahí en adelante el desarrollo de la cultura europea postdescubrimiento ${ }^{4}$. En el sentido que va de lo general cultural a lo particular de una obra y viceversa, observemos que la "tirantez epistemológica" entre la posición de Oviedo y su modelo manifiesto se presenta casi simultáneamente a la declaración de imitación realizada en el inicio mismo de la Historia. Advirtamos después que esa contradicción modélica básica jalona la refutación del "saber de los antiguos", inestabilizando con este encadenamiento el sistema completo.

Veamos primero la declaración de imitación: "Escribió Plinio treinta e siete libros en su Natural Historia, e yo en aquesta mi obra e primera parte de ella, veinte, en los cuales, como he dicho, en todo cuanto le pudiere imitar, entiendo hacerlo" (Oviedo, Sumario 13).

Desligarse del latín medieval y construir y desarrollar paulatinamente el volgare como forma independiente de la expresión científica eran condiciones previas del libre desenvolvimiento del pensamiento científico y de su ideal metodológico (...) En el caso del latín escolástico y el italiano moderno, las diferencias que presentan ambas lenguas no son por cierto meras disparidades de sonidos y signos; expresan respectivamente una cosmovisión distinta. De suerte que aun en este caso la lengua no se limita a servir de mero receptáculo o continente de la nueva visión sino que además contribuye con su propia formación y estructura a engendrarla (Cassirer 80).

3 De aquí en adelante todas las cursivas y negritas en el texto de Oviedo son mías.

4 Utilizo el concepto de "tensión" en el sentido de "anomalía y emergencia de los descubrimientos científicos" que le ha dado Thomas S. Kuhn en sus obras (La estructura 92-111; y La tensión 248-262). De aquí en adelante, toda mención al concepto de paradigma tiene el sentido que le dio Kuhn en la primera de estas obras. 
Inmediatamente viene la contradicción modélica, directamente referida a lo leído por Plinio y a las filiaciones o posibles concesiones presentes en su obra. La contradicción no constituye, sin embargo, el punto final en la discusión de Oviedo, en tanto es a partir de ella que el cronista establece los principios de su propio quehacer científico:

Yo no tengo necesidad de deso, pues no escribo de autoridad de algún historiador o poeta, sino como testigo de vista, en la mayor parte, de cuanto aquí tratare; y lo que yo no hobiere visto, direlo por relación de personas fidedignas, no dando en cosa alguna crédito a un solo testigo, sino a muchos, en aquellas cosas que por mi persona no hobiere experimentado. Y dirélas de la manera que las entendí, y de quién; por que tengo cédulas y mandamientos de la Cesárea Majestad para que todos sus gobernadores e justicias e oficiales de todas las Indias me den aviso e relación verdadera de todo lo que fuere digno de historia, por testimonios auténticos, firmados de sus nombres e signados de escribanos públicos, de manera que hagan fe (Oviedo, Sumario 13-14).

Además de la tajante "desautorización" apoyada en los "muchos testigos" equivalentes al "sujeto comunitario del saber" a que ya aludí, otros elementos presentes en esta cita ameritan que nos detengamos un momento más en ella. Subrayemos primero que las bases y principios expuestos hacen del pensamiento de Oviedo un sistema tempranamente fundado en la naciente epistemología moderna: esto es, en una posición individual que desecha enfáticamente la idea del conocimiento como una "experiencia de lectura" (sacra y/o profana) y propone simultáneamente una nueva concepción y valoración de la experiencia y de la comprobación directa en el ámbito general del conocimiento ${ }^{5}$. Afín a esta tendencia, ya en el primer libro de la Historia, Oviedo advierte al lector y destinatario (la Cesárea Majestad, a la comunidad intelectual adscrita a la tradición) sobre la aparición de "la cosmografía moderna y experimentada" y de su acción correctora de los errores e ignorancias constitutivas de la Antigua. Esta advertencia adiciona un elemento significativo. Por oposición a la Antigua y con toda fuerza, Oviedo le atribuye la condición de "verdad", de tal manera que no solo es moderna en el sentido de la "novedad" que entrega, sino que además, en el juego polar que 
su discurso instaura, se presenta como radicalmente cierta (Oviedo, Sumario 7). En segundo término destaquemos que las "cédulas y certificaciones" esgrimidas no solo muestran al cronista como un intelectual exaltado por la valoración social y dimensión simbólica que esta condición implica; esos documentos además lo posicionan como un sujeto de saber con el poder político sobre las estructuras sociales y administrativas imperiales para ejercer la función de conocer. La suma de las bases epistemológicas afirmadas, el amor al conocimiento vehementemente expuesto y el poder político exhibido y ejercido, sin duda invisten a Oviedo de la autoridad (poder-saber, en el sentido que Michael Foulcault dio a esta asociación) más que suficiente en la que ampara la firmeza de su refutación/“desautorización”. Ahora bien, desde el punto de vista de la historia de las ideas, lo que aquí interesa observar es la confluencia de una serie de factores (políticos, administrativos, de poder, etc.) a partir de los cuales se configura una nueva Autoridad cognitiva indisociable de la nueva frontera geográfica, científica y simbólica constituida por las Indias Occidentales ${ }^{6}$. De tal manera que si focalizamos el contexto de producción del pensamiento de Oviedo y, sobre todo, los factores que lo determinan, bien podemos decir que en este particular momento asistimos al enfrentamiento entre un pensamiento científico indiano revolucionario y un pensamiento científico europeo tradicional, del que saldrá triunfante, como sabemos, la Autoridad Indiana ${ }^{7}$. Asimismo, podemos decir que Oviedo representa ejemplarmente ese sujeto europeo del siglo XVI escindido entre su ortodoxia ideológica y la evidencia de su pensamiento científico.

6 Para el concepto de frontera cultural, véase: Elliot 71-101.

7 Esta "autoridad indiana" y todo el proceso que involucra en directa relación con la realidad y los fenómenos naturales, sin duda están relacionados con los albores de modernidad científica con la cual no se ha querido vincular. Un ejemplo de esto se encuentra en la siguiente opinión, en la cual se concibe que la modernidad en América se dio solo a nivel de los sujetos y sus mestizajes, sin incluir en esa idea de modernidad los conflictos que se estaban produciendo en el ámbito de la ciencia y el conocimiento:

Todo, paradójicamente, prefiguraba allí la modernidad. No la de los círculos letrados de Europa, la de los Galileo y de lo Descartes, sino la modernidad de un desencadenamiento brutal, provocado por el rechazo de los antepasados en la muerte eterna... La "proletarización" brutal de la mano de obra indígena, las desculturaciones y el desarraigo de los autóctonos, y el flujo de los seres que huían de las limitaciones ibéricas, actuaban en el mismo sentido (Bernard y Gruzinski 333).

Por supuesto, esta opinión esencializa en nuestra cultura esa modernidad pobre y marginal, ciertamente excluida de la prestigiosa modernidad del conocimiento. 
Si la condición y localización fronteriza de la producción intelectual de Oviedo resultan por sí solas de todo interés, adicionan además un hecho singularísimo y quizás inédito en la historia del conocimiento hasta el siglo XVI. Se trata de la incorporación de una dimensión plena y explícitamente jurídica a la actividad intelectual, que instituye en el "proceso" de conocimiento los elementos y procedimientos básicos de la autenticación judicial: la presencia del testigo, del escribano público, el testimonio y/o relación verdadera, las firmas y el acto de fe.

Este marco jurídico suscita al menos tres interrogantes: ¿Por qué se somete el conocimiento experimental directo de la realidad a la vigilancia y/o autenticación del escribano público? Y en esta circunstancia específica ¿qué es aquí lo sometido a juicio, lo enjuiciado? Finalmente, ¿cuáles son las partes en contienda?

Tratándose en este caso de "declaraciones"-en el sentido judicial-sobre la naturaleza, lo primero que podemos pensar es que lo que se afirma sobre los animales, plantas, ríos, frutos, sujetos, creencias, organizaciones sociales, etc., es de una condición tal, que debe ser respaldado con el acto de dar fe e implica asumir las consecuencias judiciales, simbólicas y trascendentes que el hecho de testimoniar involucra ${ }^{8}$. En consecuencia, resulta que lo que se dice de la naturaleza, se afirma simultáneamente ante el rey y la ley, ante Dios y los hombres. Sin embargo, en este caso especialísimo para la ley y para el conocimiento mismo, sucede que la verdad afirmada no se limita a "contradecir otra verdad", sino que, en tanto verdad, despliega una acción corrosiva a nivel profundo porque desfalca los pilares que sostienen la verdad y lo cierto hasta el siglo XVI: Dios, en primerísimo lugar y, en segundo, el saber de los antiguos. La razón de dicha desfalco fundamental radica en que, desde el punto de vista científico y/o teológico del siglo XVI, ni la Letra Sacra ni las autoridades - católicas o paganas- registran la naturaleza que en esos testimonios se afirma. O, peor aún, cuando sí realizan alguna alusión, sientan falsedades. Así las cosas, en este escenario judicial en el que en definitiva quien comparece es la naturaleza americana -o extra ecuménica-, resulta que el discurso verdadero del testigo, deja sin fundamento a la ley y conocimiento europeos.

8 Respecto de la dimensión trascendente del testimonio, véase: Ricoeur 13-22. 
Aun cuando, bien sabemos, la intención declarada del autor es la glorificación de la religión y civilización europeas, esta intención se tuerce en virtud del sistema de contradicciones que ella misma levanta. Revisemos paso a paso cómo y por qué los principios epistemológicos de la General Historia de Las Indias traicionan su propósito ideológico esencial y abren una falla irreparable en el horizonte paradigmático del siglo XVI. Volvamos al libro primero de esta obra y recordemos la aclaración de la disciplina y materia que va a tratar -la moderna cosmografía y las Indias Occidentales. Por sí solo este hecho pareciera no tener nada de extraordinario respecto de las prácticas textuales de la época, sin embargo, en este caso, lo significativo es que esa aclaración involucra un cambio sin precedente en la orientación del conocimiento. Concretamente, la fuerte asociación entre una y otra determina que la verdadera ciencia y el "nuevo mundo" sean elementos correspondientes, en el sentido en que ese "nuevo mundo" es decible, si y solo si, se cumple la contradicción de la nueva y verdadera ciencia. De la manera en que se enuncian ciencia y objeto a conocer, a la mentalidad europea necesariamente se le impone una paradoja sin posible resolución en el momento. Esto es que: la verdad científica es la que proviene del mundo desconocido (o extra ecuménico) y no del conocido (ecuménico); asimismo, que esa verdad está medularmente ligada a su autorrefutación y no a sus siglos de saber ${ }^{9}$ :

\section{$(\ldots)$}

Quiero significar y dar a entender por verdadera cosmografía, que aquí yo no tracto de aquestas Indias (orientales) que he dicho, sino de las Indias, islas e tierra firme del mar Océano, que agora está actualmente debajo del imperio de la corona real de Castilla, donde innumerables e muy grandes reinos e provincias se incluyen... (Oviedo, Sumario 7).

Teniendo en cuenta el marco jurídico explícito en que se están desenvolviendo los cambios epistemológicos, la localización geográfica fronteriza en la cual se realizan y la dimensión simbólica que está siendo afectada, sin duda que las aclaraciones y declaraciones de Oviedo se presentan como un hito que marca un antes y un después en la cultura, y acarrean consecuencias

9 Como se verá más adelante, en el registro de la invalidación de la ciencia europea, hay que adicionar lo que corresponde a la insuficiencia de la medicina. 
desestabilizadoras para la conciencia europea postdescubrimiento, como, por ejemplo, que sea precisamente lo ignoto-nuevo, en el sentido de lo teológicamente espurio y maligno -según el mismo Oviedo-, la fuente de donde emanan los elementos que le vienen a entregar la verdadera imagen de la tierra.

En el orden textual, las aclaraciones hechas tienen un lugar relevante, puesto que con ellas el cronista inicia una obra cuya elaboración le ha tomado, según dice, toda su vida. Más allá de los fines cortesanos involucrados en la presentación de la obra como "servicio", lo que nos interesa es que con ellas Oviedo establece los ejes de su situación intelectual en al menos dos órdenes igualmente importantes y causales: a) declara que, como sujeto histórico, pertenece al grupo de hombres de acción que, desde la perspectiva de la ciencia, está llevando a cabo un cambio paradigmático: la "Revolución Geográfica" ${ }^{10}$; b) por lo tanto, como intelectual, en la obra que sigue, va a proponer las bases de un nuevo saber -igualmente revolucionario- sin autoridad previa y obediente solo al criterio de la experiencia -en primer o segundo grado- de un "Yo". Sin duda, para la historia de las ideas científicas y de las mentalidades la novedad que aquí se encuentra no es menor, pues al negar la autoridad y descartar el conocimiento previo, en el cronista indiano -o cronista de la nueva frontera científica y simbólica- vemos despuntar el "Yo moderno" del conocimiento sin antecedente, quien, desde su individualidad, prefigura la orientación cartesiana que luego dará lugar al pensamiento filosófico moderno.

Como resulta necesario a esta transformación del sujeto, en el párrafo siguiente Oviedo enuncia una nueva actitud humana frente al conocimiento, tan ajena a la condena platónica del saber experimental, como distante de la revelación de la ortodoxia escolástica de la edad media y gran parte del renacimiento; es decir, ajena al paradigma de la Europa predescubrimiento: “(...) pues naturalmente todo hombre desea saber, y el entendimiento racional es lo que le hace más excelente que a otro ningún animal; y en esta excelencia es semejante a Dios en aquella parte que Él dijo: "Hagamos al hombre a nuestra imagen y semejanza" (Oviedo, Sumario 7).

Al igual que cualquier hombre de su tiempo, inmerso en un quiebre paradigmático del cual no vislumbra sus consecuencias más profundas, Oviedo intenta instalar la "moderna cosmografía" en relación con un nivel

10 Para el concepto "Revolución Geográfica”, véase: Randles 160-169. 
trascendente en el cual Dios ocupa el lugar del "Divino Conocedor". No percibe nuestro cristiano cronista que todo su pensamiento sobre lo que debe ser la ciencia, sus principios, métodos y objeto, están en conflicto con el relato bíblico, por la sencilla razón de que ese objeto caduca ese relato, así como prescribe en el orden de la ciencia la autoridad de su divino autor. No obstante este aparente callejón sin salida para un sujeto imperial español del siglo XVI, lo que se encuentra en el deseo natural de saber y en la "relación de semejanza" de Oviedo, es la proposición de un "nuevo pacto epistemológico" entre Dios y el hombre, en el cual se "legaliza" el (nuevo) saber experimental-científico, y se acepta a como dé lugar que el hombre conozca por sí solo, racionalmente y sin revelación, la naturaleza que Dios no anunció en las Sagradas Escrituras. Lo que se lee en la letra chica de ese nuevo contrato, es que esas Escrituras -incluyendo las de los antiguos- ya no son paradigmáticas para un sujeto y para un saber que deben explicar un objeto dejado de lado por un Dios "olvidadizo" y asumir la enorme tarea de colocar piezas desconocidas en el rompecabezas en que se ha convertido de pronto la naturaleza. Tampoco se vislumbra en ese momento que quienes suscriben el contrato de Oviedo son dos personajes debutantes, cuya notoriedad alcanzará su plenitud en la modernidad: el dios disminuido y el hombre desamparado.

Aparece con este sujeto un elemento poco común al ejercicio intelectual, en tanto adquiere la forma enunciativa característica con que los protagonistas de la conquista enaltecieron sus acciones: la hazaña, transformada desde su sentido bélico conquistador a "la hazaña humana del conocimiento". Pero contrariamente al espíritu triunfal exhibido por Hernán Cortes, podemos aproximar la hazaña de Oviedo al expediente de los "trabajos" que aparece, por ejemplo, con Pedro de Valdivia, y denominarla "los trabajos del conocimiento" 11 . Esta transformación permite vislumbrar que el "nuevo pacto epistemológico" de Oviedo involucra, a su vez, la creación de una "nueva teodicea del saber".

11 Parafraseo aquí la caracterización que hace Lucía Invernizzi de la modalidad épica presente en las Cartas de Fundación de Pedro de Valdivia ("Los trabajos" 7-15; y "El discurso" 209-229). La alusión a los esfuerzos y males padecidos en el proceso de conquista, como se sabe, es común a todos los discurso, relaciones y "verdaderas historias" escritas durante su desarrollo. 
Desta causa (se refiere a la relación de semejanza con Dios a través del conocimiento), no se contenta nuestra voluntad ni se satisface nuestro ánimo con entender ni especular pocas cosas, ni con ver las ordinarias o próximas a la patria, ni dentro della misma. Antes, por muy apartadas provincias peregrinando (los que más participan deste lindo deseo), pospuestos muchos y varios peligros, no cesan de inquirir en la tierra y en la mar las maravillosas e innumerables obras que el mismo Dios y Señor de todos nos enseña para que más lores le demos, satisfaciendo la hermosa cobdicia desta peregrinación nuestra (Oviedo, Sumario 7).

La hermosa cobdicia de conocer no es otra cosa que la constante actualización humana de la relación de semejanza entre el hombre y Dios, y en ese sentido revierte la horrorosa cobdicia de conocer bíblica que tan funestas consecuencias trajo a la humanidad. No obstante el nuevo pacto de Oviedo introduce ese signo positivo, también se tropieza con la contradicción básica subyacente a todo su pensamiento, pues la realización conceta del pacto aparece para el hombre europeo con el sino de una peregrinación peligrosa hacia lo desconocido y/o lejano de la patria, y bajo la condición del extrañamiento $^{12}$. En qué consiste ese peligro asociado al-verdadero-conocimiento, pronto va a ser clarificado por Oviedo:

Conténtese el lector con lo que yo he visto y experimentado con muchos peligros, lo goza él y sabe sin ninguno; y que lo puede leer sin que padezca tanta hambre y sed, calor e frío, con otros innumerables trabajos

(...)

... las cuales (la materia de sus libros) no he sacado de dos mil millares de volúmenes que haya leído, como en lugar suso alegado Plinio escribe (...) yo acumulé todo lo que aquí escribo, de dos mil millones de trabajos e necesidades e peligros en veinte e dos años e más que ha que veo y experimento por mi persona... (Oviedo, Sumario 11).

12 En el sistema cristiano ese extrañamiento puede leerse en las coordenadas de una nueva expulsión, como si el europeo de la época no pudiera percibir la ciencia y su saber sino bajo la condición del castigo. 
Además del conocimiento como peligro y padecimiento físico, aparece un impedimento que el nuevo sujeto de conocimiento no logrará sobrepasar "ni con dos mil millones de trabajos" y por eso constituye en definitiva el pathos de la nueva teodicea del saber: la infinidad o sinfín del objeto de conocimiento. La condición inabarcable -inconquistable- de la naturaleza, así como contradice categóricamente la fe renacentista en la suficiencia de la razón, doblega su idea de sujeto, en el sentido en que es la nueva naturaleza y no el Dios revelador quien pone el límite a la razón y dominio humanos. Este rasgo del pensamiento de Oviedo sin duda hace de él un intelectual mucho más cercano al pensamiento angustiado de Blais Pascal ${ }^{13}$, que al optimismo filosófico del renacimiento, pues las distancias celestes infinitas que el hombre barroco va a enfrentar con el advenimiento de la nueva astronomía, son experimentadas antes en la cosmografía bajo la forma de la inabarcabilidad o inconmensurabilidad de lo natural.

Desestabilizada la balanza entre la capacidad de conocer y el objeto a conocer, la inabarcabilidad natural pronto se hace visible en los difundidos herbarios del s. XVI, en donde adquiere la forma del crecimiento exponencial y caótico de las especies. Así expresa Oviedo la limitación humana:

... sé que hay en este imperio de la Indias... tan grandes reinos e provincias, y de tan extrañas gentes e diversidades e costumbres y ceremonias e idolatrías apartadas de cuanto estaba escrito, desde $a b$ initio hasta nuestro tiempo, que es muy corta la vida del hombre para poder ver ni acabar de entender o conjecturar.

¿Cuál ingenio mortal sabrá comprender tanta diversidad de lenguas... ¿Tanta variedad de animales... ¿Tanta multitud inenarrable de árboles...¿Cuántas plantas y hierbas útiles... ¿Tanta diversidad de aves... ¿Tantas montañas... ¿Cuántas vegas y campiñas... ¿Cuántos montes... ¡Cuántos valles, e flores, llanos... ¡Cuántas costas... (Sumario 8).

Y así sucesivamente, en términos de lo innumerable e inabarcable, de lo infinito-imposible al conocimiento del hombre, siguen los peces, los minerales, los ríos, etc. Y más allá de lo innumerable, comienza otra infinitud:

13 Recordemos que en el pensamiento de Pascal, el hombre se encuentra perdido entre dos infinitudes: la celeste y la de la materia. 
lo desconocido: "Cuántas otras innumerables que a él (al hombre) no son conocidas y con tantas diferencias..." (8).

El control sobre la naturaleza solo aparece en el discurso de Oviedo cuando refiere a las especies traídas por el sujeto europeo al "nuevo mundo" y bajo la forma de naturaleza-producción, es decir, de lo útil controlable y/o contable racionalmente, de tal modo que esas especies no son "multitudes inenarrables" sino "ganados útiles al servicio de los hombres", etc.

A partir de estos antecedentes, lo "desconocido natural" se presenta en el discurso de Oviedo como una fuerza que afecta otras dimensiones del quehacer intelectual del sujeto. Una de ellas, como sabemos, es la desestabilización de su lenguaje civilizado por efecto de la resistencia del nuevo objeto a ser nombrado y/o traducido al logos europeo. Este "blindaje silencioso" del objeto, que obliga a Oviedo a hablar en "el lenguaje del otro" (del indio denigrado-demonizado) y a contaminar su obra con el uso de "barbarismos", coloca al cronista de la corona en una situación muy incómoda, en la cual se ve forzado a defender precisamente aquello que lo identifica: su condición de intelectual y su estatus de cortesano; es decir, de sujeto europeo civilizado esencialmente opuesto al bárbaro.

En defensa de su registro lingüístico, Oviedo recurre a la tradicional oposición entre la "artificiosidad poética" y "la verdad" del lenguaje científico, sin percatarse, al parecer, que en este último ámbito se ubican sus barbarismos.

En cualquier caso, la autodefensa de Oviedo sobrepasa los territorios formales poéticos tradicionalmente asociados al tópico de "lo indecible" y cobra gran interés epistemológico, porque forzado por "lo indecible" el enunciante tiene que justificar el uso de "barbarismos" en una obra situada en el nacimiento de una nueva y verdadera ciencia de la naturaleza. No obstante los -confusos- esfuerzos de Oviedo por por alejarse del registro poético, poesía y epistemología no dejan de enzarzarse en su discurso, en tanto el objeto del que se quiere hablar opone la resistencia de "lo existente innombrable", o lo que solo adquiere existencia a través de complejas cadenas metafóricas. El asunto aquí es que lo "indecible" instalado en el campo de la ciencia impone al discurso científico la condición poética -metafórica-, del mismo modo que obliga al sujeto europeo a abandonar su logocentrismo si es que quiere decir la verdad sobre lo real o siquiera aproximársele.

Sujetada la posibilidad de conocer por la cláusula de la contaminación con "el otro" y su saber, en la Historia Natural y en el Sumario de la Natural Historia de las Indias tenemos que la "moderna cosmografía", la nueva 
imagen de mundo y el lenguaje plagado de barbarismos, configuran en su conjunto una novedad cultural que entra en irreconciliable conflicto con el paradigma científico anterior, con la imagen de mundo clásica y/o ecuménica y con el lenguaje "puro". Al final de la conflagración entre lo mixturadobárbaro (novedad) y lo homogéneo-civilizado (unidad), triunfará "la verdad" proveniente del primero de estos ordenes, y la correcta imagen de la tierra será construida y enunciada por un lenguaje barbarizado. Esta circunstancia provee un matiz diferente a la relación verdad (logocéntrica)-falsedad (bárbara) y a la polaridad civilización-barbarie, que tan negativamente el logocentrismo europeo ha hecho pesar sobre nuestra cultura.

Escuchemos la autodefensa del cronista:

... porque, éstos que aquí yo escribo no son de mucha industria o artificio ni de calidad que requieran prolija oración e ornamento de palabras, no han sido poco laboriosos, ni con la facilidad que otras materias se pueden allegar e componer escriptos; pero es, a lo menos, muy apacible lección oír y entender tantos secretos de Natura.

Si algunos vocablos extraños e bárbaros aquí se hallaren, la causa es la novedad; y no se ponga a la cuenta de mi romance, que en Madrid nascí, y en la casa real me crié, y con gente noble he conversado, e algo he leído, para que se sospeche que he entendido mi lengua castellana... y lo que hobiere en este volumen que con ella no consuene, serán nombres o palabras por mi voluntada puestas, para dar a entender las cosas que por ellas quieren los indios significar (Sumario 30).

No deja de suscitar una sonrisa indulgente la afirmación de la voluntad hecha por Oviedo, cuando lo cierto es que su voluntad -renacentista y católica- ha sido totalmente doblegada por la realidad natural y lingüística a la que se enfrenta, pues si no nombra con "vocablos extraños e barbaros" no podría construir su nuevo saber, el que, como bien dice, proviene en gran medida de lo que el indio-bárbaro quiere significar.

Pues bien, si respecto de la norma lingüística efectivamente Oviedo es, como él mismo se encarga de señalar, un intelectual que tiene que expresarse en un lenguaje "extraño" a la norma -cortesana, europea y letrada-, como hombre de ciencia presenta y defiende un pensamiento "desviado" respecto de los dos conceptos con que se había enunciado la tierra hasta ese momento: el cosmos griego y el mundo latino. Cierto es que Oviedo no elabora con claridad un tercer concepto esclarecedor de aquello que se esfuerza en nombrar, 
y su pensamiento va y viene entre dos enunciados borrosos y de distinta índole: la Tierra Firme y el imperio de Sus Majestades. Precisamente por esa incertidumbre la Historia Natural constituye un esfuerzo por aproximarse a esa enigmática -y barroca- "composición visible" que es para el europeo en ese momento nuestro planeta:

(...) de la universal redondez, a quien los griegos llaman cosmos e los latinos mundo. En la cual, mucho menos de la quinta parte algunos cosmógrafos quieren que sea habitada; de la cual opinión yo me hallo muy desviado, como hombre que, fuera de todo lo escrito por Ptolomeo, sé que hay en este imperio de las Indias... tan grandes reinos e provincias, y de tan extrañas gentes e diversidades e costumbres y ceremonias e idolatrías apartadas de cuanto estaba escripto, desde ab initio hasta nuestro tiempo... (Oviedo, Historia 8 ).

En la cita anterior sobresale un hecho relacionado con esa nueva teodicea del conocimiento que advertimos en Oviedo. Como él dice, todo lo que sus ojos observan en la "composición visible" -itraducible por "tierra", "mundo", "cosmos"?- se encuentra apartado, fuera, de lo escrito desde $a b$ initio $^{14}$ hasta sus días. En estricto rigor esto significa que ha estado fuera del registro de los escritos filosóficos, de los científicos y de las Sagradas Escrituras, de tal manera que la "composición visible" misma no tiene registro divino (teológico) ni humano (cultural). En relación con la teodicea del conocimiento que venimos señalando, lo que interesa es que tanto la "composición visible" como la actividad intelectual de Oviedo se instalan en un vacío: de letra, de lengua y de conocimiento, pero sobre todo, de cualquier principio trascendente creador, organizador y enunciador.

En virtud de ese vacío o ausencia inicial claramente advertidos, sobre los cuales sin embargo levanta su sistema de conocimiento, es que Oviedo deja de ser un intelectual europeo ejemplar-cortesano, católico, etc.- de su época, para convertirse en un intelectual emblemático de la modernidad, caracterizada principalmente por su vacío de centro rector, ya sea teológico, cosmológico o de la representación.

No obstante ese vacío, el esfuerzo de nuestro cronista es establecer ese "lugar otro" -fuera del cosmos, del mundo, de la escritura grecolatina, de la

14 Ciertamente, ese ab initio genera muchos interrogantes, pues no sabemos con seguridad a qué se refiere, si a la escritura misma, a la creación o a qué. 
escolástica y de la sacra- desde donde escribe y del cual escribe y que define por exclusión: ese territorio-objeto de conocimiento, afirma categóricamente, no es ni Europa, ni Asia ni África; es decir, no pertenece a la ecúmene ni al cosmos grecorromano y sin embargo es habitable.

Si bien lo que fue para Oviedo una forma de establecer el "lugar otro" se convirtió en una marca de fundación del "nuevo mundo" y en una forma permanente de relación entre "los mundos", el asunto ausencia ab initioexclusión-habitabilidad nos permite abordar otro aspecto que vincula el pensamiento de Oviedo con el surgimiento de la modernidad y sus conflictos básicos. Se trata tanto del desajuste de la obra respecto del plan modélico de conocimiento, como de una peculiar insistencia en consumar el vaciamiento del modelo mismo. Sabemos que entre las -divinas-autoridades que afirmaban la inhabitabilidad de la zona tórrida se encuentra Plinio, el Modelo que en virtud de las evidencias experimentales perdió su relación básica con la verdad. De esta manera, en la Historia se genera una dinámica singularísima que, al afirmar el Modelo (Plinio) y desmentir sus contenidos fundamentales, produce simultáneamente su vaciamiento. Lo significativo de todo esto, es que a partir de ese movimiento se comienza a operar con la "superficie" o "apariencia modélica": "(...) ignorantes del todo los antiguos, decían ser inhabitable naturalmente la dicha tórrida zona y equinoccial línea. Todo esto depongo y afirmo como testigo de vista, y se me puede mejor creer que a los que por conjeturas, sin lo ver, tenían contraria opinión" (Sumario 119).

El vaciamiento de los modelos en el orden del conocimiento es un proceso coincidente con el que experimenta el ámbito estético de la primera mitad del siglo XVI y que reconocemos como Manierismo; movimiento artístico este severamente criticado y estigmatizado por retorcer el Modelo de representación clásico en un "gesto vacio" y por su conflictiva relación con la naturaleza. Un análisis comparado entre las transformaciones que experimenta el arte de la primera mitad del siglo XVI y las del sistema del conocimiento del mismo periodo arroja interesantes similitudes, sin embargo, por el momento me limito a señalar que esta coincidencia entre plástica y epistemología expresa el "derrumbe modélico" que anuncian el inicio de una nueva era.

Conviene notar además que Oviedo no se contenta con "deponer" todo el saber de los antiguos, también invalida las instituciones que lo transmiten: Salamanca, Bolonia, París, etc., y no solamente eso; en este orden de cosas profundiza hasta lo irremediable uno de los elementos más críticos padecido por el paradigma vigente hasta mediados del siglo XVI: la 
ruptura entre el saber sobre el mundo y la escritura que lo contenía; entre la palabra de conocimiento y la cosa a conocer. Con esta brecha, el universo cultural simbólico que existió hasta el Renacimiento y que se sostuvo en la coincidencia entre palabra y mundo, queda atrás: “...ni porque uno estudie la Cosmografía y la sepa muy mejor que el Tholomeo, no sabrá, con cuantas palabras están escriptas, navegar hasta que lo use. Ni el que lee Medicina..." (Sumario 40).

La complejidad del pensamiento de Oviedo no se termina aquí. Adquiere su mayor grado de tensión cuando revela la condición vital e intelectual característica del sujeto moderno que, enfrentado a la realidad, no solo deroga el conocimiento que le precede, sino que además cuestiona las propias bases sobre las cuales funda y valida su ejercicio de conocer.

En la cita anterior ya tenemos un ejemplo de la fórmula lingüística utilizada por Oviedo para cuestionar los principios epistemológicos heredados de la Antigüedad y luego los suyos propios. Se trata de la forma negativa "ni", referida inicialmente a la escritura y a la lectura. Esta negación que se repite sin pausa a lo largo de la Historia y del Sumario, adquiere dimensiones dignas de mención cuando Oviedo aborda, por ejemplo, la cuestión de las mareas:

... no es cosa para dejar en el olvido, ni de pequeña admiración, lo que agora diré que he visto de la Mar Océana en el flujo o reflujo de su crecer o menguar; porque hasta agora ningún cosmógrafo, ni astrólogo, ni el hombre experto en las cosas de la mar, ni algund natural, de muchos a quien lo he preguntado, me ha satisfecho ni dado razón conveniente de la verdadera causa que pone en efecto lo que mis ojos muchas veces han visto y es el misterio aqueste (Sumario 40).

En el Sumario detalla quiénes son esos hombres expertos: "ni piloto(s) ni marinero(s)". Descontados los antiguos cosmógrafos y los astrólogos, resulta además que los sujetos de experiencia, los testigos de vista, quienes llevan a cabo la Revolución Cosmográfica e instauran las bases de la nueva ciencia son igualmente incapaces de dar una explicación a este y otros fenómenos naturales. De tal manera: (a) el nuevo sujeto de conocimiento (el testigo de vista); (b) la base epistemológica (la experiencia misma) y (c) la categoría de verdad (lo contrastado experimentalmente), que en su conjunto constituían los fundamentos del sistema de conocimiento propuesto por Oviedo, a su vez son invalidados por la fórmula negativa "ni". 
Este estado de profunda incertidumbre, en el que el sujeto no solo deroga las bases del saber anterior a él, sino que, además, experimenta la extrema precariedad de las propias, alcanza sus niveles más críticos en el Sumario cuando implica al mismo sujeto enunciante, a Oviedo mismo: "Pero éste ni otro de los que yo he visto ni oído ni leído..." (Sumario 112).

Ni lo visto, ni oído ni leído, que en su forma positiva, lo visto, lo oído, lo leído, fueron propuestos en los proemios como las bases del nuevo saber verdadero, resultan a muy poco andar insuficientes para aprehender y explicar la realidad. Esta circunstancia provocada - entre otros- por el mismo Oviedo, efectivamente anticipa el principio de incertidumbre que caracteriza la situación intelectual y vital del hombre moderno: nos referimos a esa transformación en virtud de la cual el sujeto histórico de conocimiento se convierte en el testigo de su propia precariedad y expresa la limitación de sus fundamentos: "Con algunas personas de grandes letras he todo aquesto platicado: no me ha satisfecho, o porque no lo alcanzan, o porque no se lo he sabido dar a entender...Yo he puesto aquí esta quistión como testigo de vista; de la absolución della no he sido digno hasta agora..." (Oviedo, Historia 41).

Respecto de lo que la relativización postdecubrimiento trajo y dejó como rasgo permanente de la modernidad, también vemos en Oviedo una reacción y una postura propias del sujeto y pensamiento científico moderno: la primera de ellas es un explícito y profundo estado de insatisfacción vital; la segunda es la renuncia definitiva a conocer "las causas últimas".

La frustración de Oviedo se vuelve, precisamente, contra lo que Plinio representa y descarga en él lo que desde la actualidad podemos llamar "la furia contra el modelo". Veamos cómo se expresa esto en el texto: "Esto que dice Plinio... cosas son muy notables. Pero yo no tengo por cierto que... Ni tampoco me satisface que diga Plinio... Ni tampoco me satisface que él diga... ni le concedo... no como él presume... lo que Della él escribe también lo tengo por incomprensible al ingenio humano" (Historia 42).

En cuanto a la renuncia humana a conocer "las causas últimas", Oviedo se encuentra a medio camino entre la idea de un Dios antojadizo - que desde la perspectiva de un sujeto del s. XVI tiene que seguir siendo el conocedor del funcionamiento de la naturaleza, aunque por misteriosos motivos no lo comunique - y la aceptación del límite científico del conocimiento ante una naturaleza que no se ofrece por sí sola ni por mandato divino a la racional 
indagación del hombre. De manera curiosa pero con evidente temor, expresa su propia renuncia atrayendo una falaz leyenda sobre Aristóteles, según la cual el gran filósofo se entregó a la muerte persiguiendo "la causa última" que explicaría el asunto de las mareas que tanto obsesiona al mismo Oviedo:

(...) e así me paresce a mi que de aquí nace la especial natura que esto causa, o, mejor diciendo, si esto no es la razón dello, será aquella causa de las causas que es el mismo Dios, que así le plugo ordenarlo. Cuanto más que, para lo que yo ignoro en este caso me desculpa Aristótiles con su muerte: en la cual yo no le pienso imitar investigando en estos secretos... (Historia 43 ).

La negación presenta en Oviedo otros aspectos dignos de revisar. La Historia no solo muestra que cuatro años después de 1492 el fenómeno de la epidemia alcanzó una escala global; desde la misma fecha notifica la insuficiencia de la medicina europea para enfrentar la enfermedad. Este hecho decisivo desequilibra más aún la relación logocéntrica civilización-barbarie que ya revisé y lo hace en tal medida que obliga a Oviedo a reconocer y proponer otra práctica curativa basada en conocimiento herbario de los indios, es decir, en "el conocimiento del otro":

Primero está el relato de la "plaga":

E desde a pocos meses, el año susodicho de mil cuatrocientos noventa y seis, se comenzó a sentir esta dolencia entre algunos cortesanos; pero en aquellos principios era este mal entre personas bajas e de poca auctoridad e así se creía que la cobraban allegándose a mujeres públicas, e de aquel mal tracto libidinoso; pero después extendióse entre algunos de los mayores e más principales (Oviedo, Historia 54).

Ahora lo que nos interesa: la incapacidad de la ciencia médica europea para hacerse cargo de un mal contagiosos proveniente del "otro mundo": "Fue grande la admiración en cuantos lo vían, así por ser el mal contagioso y terrible como porque se morían muchos desta enfermedad. E como la dolencia era cosa nueva, no lo entendía ni sabían curar los médicos, ni otros, por experiencia, consejar en tal trabajo" (Historia 54).

El asunto que importa aquí es que respecto de la capacidad de conservar la vida humana, el saber científico europeo tradicional, al igual que el nuevo fundamento epistemológico de la experiencia, quedan nulos. Inmediatamente después de constatar con la muerte de muchos la insuficiencia de la ciencia médica europea, Oviedo anuncia que en las Indias sí existe una medicina 
herbaria capaz de sanar esa plaga y otras enfermedades ${ }^{15}$. La posibilidad curativa esperanzadora pone en evidencia un hecho profundamente perturbador para la conciencia europea precolombina logocéntrica de la época: el hecho es que el hombre europeo no solo se encuentra ante una plaga desconocida, sino que debe aceptar la existencia de "otro saber" no europeo, no grecolatino, no católico, suficiente para salvarle la vida. Un saber del cual desconoce sus fundamentos divinos y/o mágicos y las relaciones micro-macrocósmicas que establece entre la naturaleza, el cuerpo humano y los astros. Así atrapado entre la muerte y la aceptación del saber (demoníaco) del "otro", el sujeto europeo deja de ser el único sujeto de conocimiento, pues en no pocas ocasiones debe recurrir a este saber bárbaro-demoníaco y someterse a sus métodos si quiere conservar la vida; más aún, debe reconocer la superioridad de ese saber sobre el suyo: “(...) e sábense curar (los indios), e tienen muy excelentes hierbas e árboles e plantas apropiadas a esta y otras enfermedades..." (Oviedo, Historia 54).

Otro asunto que aparece en la obra de Oviedo y que afecta a la cultura de su época es la diferencia o el "desvío" que presenta el cielo del "nuevo mundo". Recordemos que para la ciencia medicinal basada en el sistema de la semejanza eran importantes las relaciones formales y las dinámicas de atracción entre las hierbas y las estrellas. En este punto Oviedo no se diferencia un ápice de la conciencia común de su tiempo y bien lo deja ver cuando se refiere a las propiedades medicinales del imán (Historia 44). Sin embargo, este complejo sistema de atracciones y la idea de la correspondencia que lo sustenta, van a perder pie cuando oímos decir al mismo cronista que de esta parte de la "composición visible" las estrellas no solo no son fijas y presentan un comportamiento desviado:

Por manera que, pues todas estas mudanzas e desvíos face la estrella, no es ella el polo ni es fija ni sería medida cierta para los navegantes.

$(\ldots)$

15 Por poner solo un ejemplo, cito lo que dice Oviedo en el Sumario a propósito de los cocos: “...los que acostumbran a beber en aquellos vasos, y son dolientes de ijada, dicen que hallan maravilloso y conocido remedio contra tal enfermedad, y rómpeseles la piedra a los que la tienen, y hácela echar por la orina" (209). Alusiones como esta a distintos remedios y al saber medicinal del "nuevo mundo" son constantes a lo largo de las dos obras de Oviedo. 
Toqué esta particularidad de las estrellas, porque son muy notable figura en el cielo; en el cual hay otras innumerables que se ven poco... verán el cielo tan lleno de estrellas como está sobre España, en diferentes intervalos o figuras que no se ven ninguna dellas desde España, ni desde parte de toda la Europa, ni en la mayor parte de Asia ni África... (Historia 45).

Como corolario tenemos un cielo mudable y desviado en el que las estrellas componen otras figuras distintas a las del cielo europeo renacentista, medieval y grecolatino. Se trata de un cielo fuera del cielo, exógeno del cielo europeo, asiático y africano -como la geografía-, extraño al de la ecúmene, a través del cual el europeo no sabe navegar ni desplegar su mapa de correspondencias. Un cielo que aparece como cifra del desvío del lenguaje, del pensamiento y de la ciencia.

\section{BIBLIOGRAFÍA}

Arrom, José Juan. Imaginación del nuevo mundo: diez estudios sobre los inicios de la narrativa hispanoamericana. México: Siglo XXI, 1991.

Benjamin, Walter. "La obra de arte en la época de su reproductibilidad técnica". Discursos interrumpidos I. Filosofía del arte y de la historia. Pról., trad. y notas Jesús Aguirre. Buenos Aires: Taurus, 1989.

Bernard, Carmen y Serge Gruzinski. Historia del Nuevo Mundo. Tomo II. México: Fondo de Cultura Económica, 2005.

Bolaños, Álvaro. "La crónica de Indias de Fernández de Oviedo: ¿Historia de lo general y natural, u obra didáctica?" Revista de Estudios Hispánicos 25/3 (1991): 15-33.

Cassirer, Ernst. Individuo y cosmos en la filosofia del Renacimiento. Buenos Aires: Emecé, 1951.

Da Silva Dias, J.S. Influencia de los descubrimientos en la vida del siglo XVI. México: Fondo de Cultura Económica, 1986.

Díaz del Castillo, Bernal. Historia verdadera de la conquista de España. México, D. F.: Editorial Porrúa, 1970.

Elliott, J.H. El viejo y el nuevo mundo (1492-1650). Madrid: Alianza Editorial, 1972.

Gerbi, Antonello. La disputa del Nuevo Mundo. México: F.C.E, 1960.

La Naturaleza de las Indias. México: F.C.E, 1962.

Henríquez Ureña, Pedro. La cultura y las letras coloniales en Santo Domingo. Buenos Aires: Universidad de Buenos Aires, Instituto de Filología, 1936.

Hull, L.W. H. Historia y Filosofía de la Ciencia. Trad. Manuel Sacristán. Barcelona: Ariel, 1989. 
Invernizzi, Lucía. “"Los trabajos de la guerra” y "Los trabajos del hambre”: dos ejes del discurso narrativo de la Conquista de Chile (Valdivia, Vivar, Góngora Marmolejo)". Revista Chilena de Literatura 36 (noviembre 1990): 7-15.

"El discurso argumentativo en las Cartas II y VIII de Pedro de Valdivia". Boletín de Filología XXXV (1995-1996): 209-229.

Kuhn, T. S. La estructura de las revoluciones cientificas. México: Fondo de Cultura Económica, 1986.

La tensión esencial. México: Fondo de Cultura Económica, 1982.

Miranda, José. "Introducción”. Oviedo, G. Sumario de la Natural Historia de las Indias. México: F.C.E, 1979. 7-74.

O’Gorman, Edmundo. Cuatro Historiadores de Indias. Siglo XVI. México: Sep/Setentas, 1972.

Oviedo Fernández, Gonzalo de. Historia General y Natural de Las Indias. Ed. y Pról. Juan Pérez de Tudela Bueso. Madrid: Biblioteca de Autores Españoles, 1959.

Sumario de la Natural Historia de las Indias. Ed., Intr. y notas, José Miranda. México: Fondo de Cultura Económica, 1950.

Pascal, Blaise. Pensamientos. Trad. Eugenio D’ors. Buenos Aires: Losada, 2003.

Randles, W.G.L. El viejo mundo y el nuevo (1492-1650) México: Fondo de Cultura Económica, 1990.

Ricoeur Paul. Texto, Testimonio y narración. Trad., Pról. y notas, Victoria Undurraga. Santiago de Chile: Andrés Bello, 1983.

Salas, Alberto. Tres cronistas de Indias. México: F.C.E., 1992.

Trabulse, Elías. Ciencia y religión en el siglo XVII. México: El Colegio de México, 1974. 